\title{
Interest and Prior Knowledge in Second Language Reading Comprehension
}

\author{
John Eidswick \\ Kwansei Gakuin University
}

The influence of interest on learning is well-established in educational psychology, but little interest research has been conducted in the field of second language (L2) learning. This study examined interest and an associated factor, prior knowledge, in relation to reading comprehension. Intermediate-level sophomore students in an English program at a private university in Japan $(N=23)$ rated their interest in and knowledge of 11 topics. Correlations between interest and prior knowledge were significant only for topics related to famous individuals. Participants read expository texts about selections from the topic list with high interest-high prior knowledge $(\mathrm{HH})$, high interest-low prior knowledge (HL), and low interest-low prior knowledge (LL), then took multiple-choice comprehension tests. Analysis of Variance (ANOVA) procedures revealed significant differences between scores for the HH text and those of the HL and LL texts. Implications of correlations and test score differences are discussed, and suggestions for future research are offered.

興味・関心が学習に影響を与えることは教育心理学において十分に立証されているにもかか わらず、第二言語(L2)の学習においては、興味・関心に関する研究は従来ほとんど行われてこな かった。本研究では、英文読解に関し、興味・関心およびそれに関連する要因である事前知識 についての調査を行った。日本の私立大学の英語プログラムにおいて、中級レベルのクラスで学 ぶ 2 年次の学生 (23名)が、11のトピックに対して自分が持つ興味・関心の高さと知識の量の格 付けを行った。興味・関心の高さと事前知識の量の間には、著名な人物に関するトピックの場合 にのみ、有意の相関が見られた。学生たちは前述のトピックの中から、興味・関心が高く事前知 識が多い $(\mathrm{HH}) 、$ 興味・関心が高く事前知識が少ない $(\mathrm{HL}) 、$ 興味・関心が、低く事前知識が少ない (LL)トピックを選び、それらに関する説明文を読んだ後、選択問題形式の読解テストを受けた。 テストの成績に対して分散分析 (ANOVA)を行った結果、HHの説明文に対する成績が、HLおよ びLLの説明文に対する成績と有意に異なっていることが明らかになった。これらの相関および テストの成績の相違が意味するものについて考察し、今後の研究への提言を述べる。

JALT Journal, Vol. 32, No. 2, November 2010 


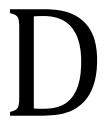

ecades of research in educational and cognitive psychology have confirmed a strong relationship between interest and learning, particularly related to reading comprehension and text-based learning. It is surprising then that so few studies have been conducted to investigate the influence of interest on second language (L2) learning.

Individuals interested in a domain, activity, topic, or thing (henceforth "object") are more persistent, engaged, and attentive when interacting with the object of interest (Ainley, Hidi, \& Berndorff, 2002; Hidi, 1990, 2000; Renninger, 2000). Interest affects choices for the direction and duration of attention (Hidi, 1990; Schraw \& Lehman, 2001). Both reader- and textbased interest have been found to positively and consistently influence comprehension and learning in a wide range of conditions and reading proficiency levels (for a review, see Hidi, 2001). The positive influence of interest has been shown to be independent of text difficulty, reading ability, and age (Schiefele, 1996). Interest likely derives its beneficial relationship with comprehension and learning from the increases in attention and engagement it generates (see Sadoski, 2001). Despite indications of a strong link between interest and comprehension in domains occurring in students' first language (L1), the results of the scant studies of interest and L2 reading comprehension (e.g., Brantmeier, 2006; Eidswick, 2009) have not clearly indicated a positive relationship between the two factors.

Interest is commonly divided into individual interest and situational interest. Individual interest is considered to be a stable and enduring inclination to reengage with specific objects (Bergin, 1999; Hidi, 1990; Hidi, Berndorff, \& Ainley, 2002; Krapp, Hidi, \& Renninger, 1992; Schiefele, 1999). Reengagement with an object of interest produces increases in knowledge about the object. Knowledge acquired from engaged, self-determined activities related to individual interest is likely to be qualitatively different from knowledge gained from academic, institutionally determined activities.

Situational interest is a usually short-lived emotional state triggered by qualities of an object. Among the qualities found to evoke situational interest are visual imagery, novelty, surprise, concreteness, and intensity (Hidi \& Baird, 1986, 1988), along with ease of comprehension (Mitchell, 1993). In developing a model of L2 learner reading interests, Brantmeier (2006) identified ease of recollection, engagement, cohesion, emotiveness, and prior knowledge as interesting in texts. In a study by Eidswick, Praver, \& Rouault (2010), intermediate university students of English in Japan, responding to selected graded readers, endorsed as interesting those books that possessed qualities that could be described with the following adjec- 
tives: exciting, mysterious, romantic, heartwarming, strange, unpredictable, funny, scary, and easy to comprehend.

Hidi and Renninger's (2006) Model of Interest Development describes a continuum with four discrete phases: triggered situational interest, maintained situational interest, emerging individual interest, and well-developed individual interest. These phases are sequential, commencing with a spark of situational interest that can lead to further contacts with an object, and eventually to strongly committed individual interest. For L2 learners, this process might commence with an initial exposure to a new language that arouses their interest, and which can be sustained by subsequent interaction with interesting materials and activities with which the language is presented, or lost when such materials or activities fail to inspire or maintain learners' interest.

\section{Prior Knowledge}

Research has demonstrated the importance of prior knowledge to a range of skills conducive to L2 text-based learning. These include the efficiency of attention allocation to input (Robinson, 2003), inference skills (Barry \& Lazarte, 1998), and reading comprehension (Carrell, 1987; Chen \& Donin, 1997; Hudson, 1982).

Prior knowledge can contribute to reading comprehension to the extent that it poses problems of test bias (Alderson, 2000). If a student does well on a reading test, is it because of strong reading ability or because of background knowledge of the reading topic or domain? A quality shaping the contribution of prior knowledge to $\mathrm{L} 2$ reading comprehension is the degree of reader familiarity with culturally related information within a text. Individuals who are unfamiliar with culture-specific textual elements are less likely to understand a text than individuals who are familiar with them (Johnson, 1981; see also Chihara, Sakurai, \& Oller, 1989).

\section{Prior Knowledge and Interest}

The condition of knowledge accumulation being a consequence of and an antecedent for interest presents complications for studies whose results signify interest effects on learning or comprehension. Does an individual's differential performance on an assessment instrument related to a highinterest object demonstrate influences of interest or of prior knowledge? While it has been shown that both prior knowledge and interest play roles in learning, research into conjunctions of these two factors has not clarified 
completely how or to what extent they are correlated in specific domains and interact to contribute to human development (for a review, see Alexander, Kulikowich, \& Jetton, 1994). Difficulty in examining the relationship between interest and prior knowledge arises in part from complexities in the constructs themselves, both of whose dimensions change depending on qualities of objects of interest and the individuals experiencing them, as well as the variable length and frequency of time of exposure and qualities of social environments in which such objects are experienced.

Results of the few interest-prior knowledge studies that have been conducted in L2 learning show little concordance. In a study of interest sources and reading comprehension with advanced native-English-speaking university students of Spanish in the United States, Brantmeier (2006) used factor analysis to designate prior knowledge as a component of situational interest, explaining $13 \%$ of its variance. Brantmeier also found that prior knowledge, as a constituent of situational interest, was positively related to reading comprehension on the 10 -item multiple-choice section of a comprehension test, but not on the total recall or sentence completion sections. Bügel and Buunk (1996) explored the role of interest and prior knowledge as related to sex differences in reading comprehension among English as a foreign language (EFL) high school students in the Netherlands. While the researchers found significant differences between females and males in prior knowledge and interest, and claim their findings are evidence of sexrelated differential effects of the two variables on reading comprehension, it is possible that reading proficiency emerged as a confound of the results. In a study examining interest, prior knowledge, and reading comprehension among English as a second language (ESL) students at an American university, Carrell and Wise (1998) found no significant effect for interest or prior knowledge on scores from 10-item multiple-choice reading comprehension tests. The researchers also found no significant correlation between prior knowledge and interest. Citing speculation by Baldwin, Peleg-Bruckner, and McClintock (1985), whose research had produced similar results among American middle-school students reading in their L1, Carrell and Wise attributed this finding to the condition that in school students sometimes are made to acquire knowledge about academic topics in which they have little interest. As the researchers provided largely academic topics (e.g., computers, human evolution, Islamic art), it is likely that when participants in this study designated their level of prior knowledge about a topic as high, the prior knowledge they identified had been acquired from experiences related to required academic study instead of individual or situational interest. This 
might in turn have contributed to a lack of significance in the comprehension test scores as they related to interest and prior knowledge.

Carrell and Wise (1998) identify as a limitation in their study a characteristic shared by many ESL classes: the heterogeneity of the participants' native languages. Evidence appeared suggesting that within groups of students from the same country (e.g., Russia), differences existed with regard to (at least) gender and reading comprehension that could have differentiated specific national groups from others and influenced the results of the study overall. The researchers recommended future studies be conducted with participants that share a common L1.

The present investigation incorporates elements of the design used in the Carrell and Wise study and includes two important modifications. First, this study was conducted with EFL participants with the same L1; and second, reading topics were used that students were unlikely to have studied without having a personal interest.

The following research questions were explored. Among EFL learners:

1. What is the relationship between interest and prior knowledge?

2. What topic qualities evoke varying configurations of interest and prior knowledge?

3. Do variable configurations of interest and prior knowledge influence reading comprehension differently?

\section{Method}

Research was conducted during the fall semester of 2009. Participants were 23 sophomore students (TOEFL ITP test scores of 430-525), majoring in humanities, an intermediate-level four-skills English class in an accelerated English program at a private university in Nishinomiya, Hyogo, Japan. Three of the students were male and the rest were female. Entry to the program is competitive, based on TOEFL scores. Students who complete the intermediate course can satisfy their 2-year university English requirement in one year.

Participants received 11 short descriptions of articles (examples in Appendix A), which they used to rate, via a 6-point Likert scale, their anticipated interest in reading. Participants were also asked to estimate their knowledge of the article topics. From the online encyclopedia Wikipedia, topics were selected whose thematic variation seemed likely to generate a wide range of interest and prior knowledge and were unlikely to be topics students had been required to study in school. Two of the topics, Takafumi Horie (the unconventional founder of the Livedoor web portal who was 
arrested for securities fraud) and Akashiya Sanma, a famous Japanese comedian, were chosen because as these figures had appeared regularly on Japanese television, participants were likely to possess prior knowledge of them, regardless of interest level. Descriptive data for participant responses to the 11 topics is presented in Table 1 .

\section{Table 1. Descriptive Statistics for Perceived Interest and Prior Knowledge}

\begin{tabular}{lcccc}
\hline Topic & \multicolumn{2}{c}{ Interest } & \multicolumn{2}{c}{ Prior Knowledge } \\
\hline & $\mathrm{M}$ & $\mathrm{SD}$ & $\mathrm{M}$ & $\mathrm{SD}$ \\
Akashiya Sanma & 4.39 & 1.44 & 3.04 & 1.11 \\
Candlemaking & 4.48 & 1.08 & 2.43 & 1.12 \\
Chocolate & 4.57 & 1.12 & 2.70 & 1.11 \\
Concrete & 2.57 & 1.61 & 1.70 & 0.93 \\
Ecocities & 3.61 & 1.23 & 2.04 & 1.02 \\
Ghosts & 4.91 & 1.08 & 2.35 & 1.30 \\
Japanese cuisine & 3.74 & 1.18 & 2.78 & 1.24 \\
Michael Jackson & 4.96 & 1.33 & 4.83 & 1.30 \\
Perfume & 4.48 & 1.20 & 2.22 & 1.00 \\
Takafumi Horie & 4.48 & 1.08 & 4.04 & 1.28 \\
Viruses & 3.61 & 1.23 & 2.04 & 1.02 \\
\hline
\end{tabular}

Topics that rated the highest on interest and knowledge ( $\mathrm{HH})$, the lowest on interest and knowledge (LL), and the highest on interest yet lowest on knowledge (HL) were chosen. To be used for the study, the HH and LL topics were required to have interest and prior knowledge ratings that were higher (in the case of $\mathrm{HH}$ ) or lower (in the case of LL) when the means were added together than any other interest-prior knowledge configurations. To qualify as HL, a topic had to have a greater difference between the means for interest and prior knowledge than other configurations. Also, the high and low figures, respectively, of the scores had to fall within the higher or lower 
half of the pertinent 6-point Likert scale. Using these criteria, the following topics were chosen: Michael Jackson (HH), Ghosts (HL), and Concrete (LL). Since no pairs of ratings met the requirements for low interest-high prior knowledge (LH), this configuration was not used.

Articles based on the three topics were prepared based on texts drawn from the entries for these topics on Wikipedia (example in Appendix B). The articles were shortened, and footnotes and hypertext links were removed. The articles were otherwise unmodified. Table 2 provides structural information about the three articles, including Flesch-Kincaid readability scales measures. The readability statistics place all the texts within the 3rd grade of the Flesch-Kincaid scale.

\section{Table 2. Article Lengths and Flesch-Kincaid Readability Scores}

\begin{tabular}{lccc}
\hline Article & $\begin{array}{c}\text { Number of } \\
\text { words }\end{array}$ & $\begin{array}{c}\text { Words per } \\
\text { sentence }\end{array}$ & Readability \\
\hline $\begin{array}{l}\text { Michael Jackson } \\
\text { (HH) }\end{array}$ & 761 & 19.3 & 60.8 \\
Ghosts (HL) & 877 & 23.7 & 54.4 \\
Concrete (LL) & 552 & 19.7 & 56.4 \\
\hline
\end{tabular}

Note. $\mathrm{HH}=$ high interest, high prior knowledge, $\mathrm{HL}=$ high interest, low prior knowledge, $\mathrm{LL}=$ low interest, low prior knowledge

In a counterbalanced manner, students were given one of the three articles in class each week, over a 3-week period. During a given session, each of the three articles was read by a third of the students, followed by randomized rotations of articles on subsequent weeks. Students were permitted to read for 15 minutes and to use dictionaries. After each reading, the articles were collected, and the participants completed a comprehension test containing 10 multiple-choice items (example in Appendix C).

\section{Results}

\section{Pre-Test Topic Ratings}

A Kolmogorov-Smirnov (K-S) procedure indicated that the interest and prior knowledge ratings for 10 out of the 11 proposed topics were non- 
normally distributed. For these 10 topics, Kendall's tau $(\tau)$, a procedure for evaluating correlation between paired variables with nonparametric distribution and one especially appropriate for small data sets (see Field, 2005) was conducted. A Pearson correlation coefficient $(r=.12)$ was produced for the only topic (Chocolate) with normally distributed data. Table 3 shows correlations for student ratings.

\begin{tabular}{lc}
$\begin{array}{l}\text { Table 3. Correlations Between } \\
\text { Knowledge Ratings of Article Topics }\end{array}$ \\
\hline Topic & $\tau$ \\
\hline Akashiya Sanma & $.46^{*}$ \\
Candlemaking & -.02 \\
Concrete & -.15 \\
Ecocities & .25 \\
Ghosts & .32 \\
Japanese cuisine & .12 \\
Michael Jackson & $.45^{*}$ \\
Perfume & .16 \\
Takafumi Horie & $.64^{*}$ \\
Viruses & -.14 \\
\hline
\end{tabular}

Note. ${ }^{*} p<.05$

* Significantly high correlation was found between interest and prior knowledge ratings on three topics: Michael Jackson, Akashiya Sanma, and Takafumi Horie.

\section{Comprehension Test Results}

The results of another Kolmogorov-Smirnov (K-S) procedure were insignificant, indicating that all three sets of test scores were normally distributed. Reliability measures (Michael Jackson: $\mathrm{a}=.740$; Ghosts: $\mathrm{a}=.717$; Concrete: $\mathrm{a}=.713$ ) for the tests indicated acceptable reliability. Descriptive statistics are provided in Table 4 . Mauchly's test was not significant $\left(\chi^{2}(2)=\right.$ $5.17, p<.05)$, indicating the assumption of sphericity was not violated. 
Table 4. Descriptive Statistics of Comprehension Scores for InterestPrior Knowledge Configurations

\begin{tabular}{lccc}
\hline Article & $\mathrm{N}$ & $\mathrm{M}$ & $\mathrm{SD}$ \\
\hline Michael Jackson (HH) & 23 & 7.73 & 1.87 \\
Ghosts (HL) & 23 & 6.53 & 2.10 \\
Concrete (LL) & 23 & 4.93 & 2.05 \\
\hline
\end{tabular}

Note. $\mathrm{HH}=$ high interest, high prior knowledge, $\mathrm{HL}=$ high interest, low prior knowledge, $\mathrm{LL}=$ low interest, low prior knowledge

A one-way repeated-measures Analysis of Variance (ANOVA) was conducted to examine the relationship between reading comprehension test scores and the three configurations of interest and prior knowledge. The ANOVA showed a significant effect, $F(2,28)=6.61, p<.05, \mathrm{w}^{2}=.27$.

A Bonferonni post hoc test revealed that the Michael Jackson (HH) article had significantly higher comprehension scores than either of the Concrete and Ghosts articles $(p<.05)$, but no significant differences were found between the scores of Ghosts and Concrete. A summary is displayed in Table 5.

\section{Table 5. Contrasts Between Interest-Prior Knowledge Configurations}

\begin{tabular}{lcccc}
\hline Comparisons & df & MS & F & R \\
\hline HH vs. HL & 1 & 21.6 & 5.56 & $.53^{*}$ \\
HL vs. LL & 1 & 38.4 & 3.55 & .44 \\
HH vs. LL & 1 & 117.6 & 9.66 & $.65^{*}$ \\
\hline
\end{tabular}

$* p<.05$

\section{Discussion}

The first two research questions of this study concerned (1) the nature of the relationship between interest and prior knowledge, and (2) the topic qualities that influenced varying configurations of interest and prior knowledge. Correlations between the two factors showed significance on only 3 of the original 11 topics. These were Michael Jackson, Akashiya Sanma, and 
Takafumi Horie. The topic which earned the highest interest-prior knowledge rating was Michael Jackson; also relatively high were Akashiya Sanma and Takafumi Horie. In other words, the topics which had statistically significant correlations were also those with the highest interest-prior knowledge configurations. This finding accords well with the conceptualization of individual interest as a cognitive and affective state which gives rise to increases in knowledge about objects of interest, and of situational interest as a phenomenon whose constituents include prior knowledge.

It is intriguing, and a finding likely of interest to any teacher who wishes to better incorporate interest as a means of facilitating classroom learning, that these three topics, in addition to garnering the highest correlations and interest-prior knowledge ratings, were also the only ones that focused on named people. It is possible that topics based on human biography heighten interest because of their perceived personal relevance or value; readers are perhaps intrinsically drawn to reading about human beings whose personal concerns or areas of endeavor they see as immediately pertinent to their own, and who become foci of social interaction via widespread media exposure. It is perhaps unsurprising that two of these three named people were Japanese celebrities who are familiar to Japanese television viewers. A reasonable conjecture would be that for many students, these famous people were objects of emerging or well-developed individual interest. Potential existed, in terms of their longevity in public life (especially in the cases of Akashiya Sanma and Michael Jackson) and relevance to the lives of Japanese university students (especially in the case of Takafumi Horie) for deliberate repeated and engaged experiences via television and other media sources. The saturation news coverage of the criminal cases involving Michael Jackson and Takafumi Horie, and, more recently, the former's death, might also have sparked situational interest components such as novelty, intensity, excitement, mystery, sentimentality, unpredictability, and (in the case of Michael Jackson) strangeness.

It is interesting to note that another topic relevant to Japanese culture, Japanese Cuisine, garnered relatively low ratings for prior knowledge. It is possible that students in this age group (who are popularly reputed to lack cooking skills) interpreted their prior knowledge of Japanese Cuisine to mean knowledge of cooking rather than eating it.

Ghosts was the topic whose responses evidenced the widest divide between high interest and low prior knowledge. Students expressed relatively high interest in three other topics that they professed relatively low knowledge about: Candlemaking, Chocolate, and Perfume. The mysterious, scary 
nature of ghosts could well have provoked sensations of situational interest, but the topics of candlemaking, chocolate, and perfume perhaps seemed interesting to participants because of personal relevance. Since chocolate and perfume are common objects, familiar to everyone, but participants claimed low prior knowledge of these objects, it is probable that prior knowledge, as in the case of Japanese Cuisine, was interpreted to mean procedural knowledge as to how the object was produced. The appearance on the alphabetical-order topic list of Chocolate, Perfume, and Japanese Cuisine after Candlemaking might have prompted participants to perceive Chocolate as chocolate making and Perfume as perfume making. By whatever means the interpretation of these topics arose, it also possible that since candlemaking, chocolate, and perfume are objects that are both exceedingly ordinary yet possess origins of manufacture that are mysterious to many people, situational interest regarding these origins was aroused.

Concrete, the topic for which participants indicated the lowest interestprior knowledge configuration, appeared to lack elements of situational interest, and it is doubtful that any participants had experienced many engaged encounters with the object of this topic, whose text, like others on the list, seems to have been anticipated as an explanation of a procedure. Few students claimed to have much familiarity with concrete, despite having walked on it while coming to class. Future research might examine the strategies that learners use to perceive intended meanings of concepts that possess multiple potential interpretations.

The results of the one-way repeated-measures ANOVA supported an affirmative answer to the third research question: configurations of interest and prior knowledge do influence reading comprehension differently. As noted, comprehension test results for the three configurations showed significant differences between the scores for Michael Jackson (HH) and both Ghosts (HL) and Concrete (LL), but not between Ghosts (HL) and Concrete (LL). Put another way, the two articles with high interest ratings produced test scores that were significantly different from each other, and one each of the high interest and low interest topics produced test scores that were not significantly different. Prior knowledge, on the other hand, consistently corresponded with the significant test score differences, suggesting that prior knowledge played a different and more influential role in text comprehension than did interest. Another possibility is that high interest and high prior knowledge interacted in a way that fortified text comprehension, and that this interaction differed qualitatively from interactions between the factors in other HL and LL configurations. Evidence for this interaction might lie in 
the finding that the interest and prior knowledge ratings for the pre-reading topic Michael Jackson correlated significantly, whereas the interest and prior knowledge of other configurations did not.

\section{Conclusion}

This study examined the bases for three configurations of high and low interest and prior knowledge prompted by nonacademic text topics, and whether these configurations differentially related with comprehension for expository texts. Participant responses to a list of text topics prompted varying interest and prior knowledge evaluations. These evaluations differed depending on whether characteristics of topics prompted perceptions of interest components such as personal relevance, mysteriousness, intensity, excitement, and unpredictability. Among the selection of 11 topics, only three related to named people, with high profiles in the media. These three topics also rated the highest on the list for high interest-high prior knowledge, suggesting that biography-related topics, especially about famous people, might be more likely to be experienced as both more interesting and more familiar than other topic categories. Analysis of multiple-choice comprehension test results revealed significantly higher scores for the high interest-high prior knowledge $(\mathrm{HH})$ text than for those of the other texts, but no significant differences between the test scores for high interest-low prior knowledge (HL) and low interest-low prior knowledge (LL) texts. One interpretation of these results is that they provide support for a positive influence of prior knowledge on reading comprehension, and do not provide support for a similar influence by interest. Another interpretation is that, given that the $\mathrm{HH}$ text was based on one of the three topics that rated highest for both interest and prior knowledge and for correlation between them, the interaction of interest and prior knowledge facilitated comprehension in ways in which insignificantly correlated configurations did not.

While the results offer insights into the relationship between interest, prior knowledge, and reading comprehension, certain limitations in the study make it difficult to make strong claims. If the number of participants had been larger, the statistical power of the procedures, and the ability to be confident of their results, would have been greater. Also, although the FleschKincaid readability formula is widely used to evaluate text difficulty, and has been shown to be consistent in predicting text difficulty (Fry, 1989), the use of the formula with L2 readers is not without controversy (see Greenfield, 2004). Future L2-interest researchers might wish to examine the dimensions of the present study in the light of different approaches to text diffi- 
culty measurements. Furthermore, because of time constraints, estimations of participants' prior knowledge in this study were limited to self-reports via Likert-scales. While agreement is lacking on the best ways to measure prior knowledge (Grabe, 2009), other approaches that examine knowledge with more depth, such as tests targeting participants' comprehension of topic-specific vocabulary, or knowledge of closely related domains, might provide a fuller picture of participant prior knowledge in future studies. Time constraints also prevented further attempts to find a topic that conformed to the prerequisites for the configuration of low interest-high prior knowledge after this configuration was not found in the ratings of the initial 11 topics. Research that incorporates this missing fourth configuration will likely extend and enrich the results of the present study, which appear to indicate differential effects for low and high prior knowledge. Limitations related to operationalization of factors in this study highlight areas for further exploration. No control was provided for the effects of covariation between factors preventing a clearer understanding of whether interactions between interest and prior knowledge could facilitate comprehension. This study operationalized text comprehension using only a 10-item multiplechoice instrument, without attempt to analyze separately and compare categories important to comprehension, such as general, specific, and inferential knowledge. In order to gain a better understanding of the relationship between interest, prior knowledge, and text comprehension, more research needs to be conducted that investigates connections between the two factors and multiple forms of text comprehension, with texts that use modalities outside of expository writing and with research designs which enable researchers to conduct more precise examination of interaction effects.

John Eidswick is an instructor of English at Kwansei Gakuin University and a doctoral candidate in TESOL. His research focuses include interest, learner autonomy, and L2 writing.

\section{References}

Ainley, M. D., Hidi, S., \& Berndorff, D. (2002). Interest, learning, and the psychological processes that mediate their relationship. Journal of Educational Psychology, 94, 545-561.

Alderson, J. C. (2000). Assessing reading. Cambridge: Cambridge University Press. 
Alexander, P., Kulikowich, J., \& Jetton, T. (1994). The role of subject-matter knowledge and interest in the processing of linear and non-linear texts. Review of Educational Research, 64, 201-252.

Baldwin, R. S., Peleg-Bruckner, Z., \& McClintock, A. H. (1985). Effects of topic interest and prior knowledge on reading comprehension. Reading Research Quarterly, 20, 497-504.

Barry, S., \& Lazarte, A. (1998). Evidence for mental models: How do prior knowledge, syntactic complexity, and reading topic affect inference generation in a recall task for nonnative readers of Spanish? The Modern Language Journal, 82, 176-193.

Bergin, D. A., (1999). Influences on classroom interest. Educational Psychologist, 34, 87-98.

Brantmeier, C. (2006). Toward a multicomponent model of interest and L2 reading: Sources of interest, perceived situational interest, and comprehension. Reading in a Foreign Language, 18, 89-115.

Bügel, K., \& Buunk, B. P. (1996). Sex differences in foreign language text comprehension: The role of interests and prior knowledge. The Modern Language Journal, 80, 15-31.

Carrell, P. (1987). Content and formal schemata in ESL reading. TESOL Quarterly, 21, 461-481.

Carrell, P. L. \& Wise, T. E. (1998). The relationship between prior knowledge and topic interest in second language reading. Studies in Second Language Acquisition, 20, 285-309.

Chen, Q., \& Donin, J. (1997). Discourse processing of first and second language biology texts: Effects of language proficiency and domain specific knowledge. The Modern Language Journal, 81, 209-227.

Chihara, T., Sakurai, T., \& Oller, J. W. (1989). Background and culture as factors in EFL reading comprehension. Language Testing, 6, 143-151.

Concrete (n.d.). Retrieved August 5, 2009, from Wikipedia: http://en.wikipedia.org/ wiki/Concrete

Eidswick, J. (2009). The influence of interest on reading comprehension in EFL students. Annual Research Report of the Language Center, 12, 25-38. Kwansei Gakuin University.

Eidswick, J., Praver, M., \& Rouault, G. (2010). Extensive reading and reading circles for ESL/EFL students. Extensive Reading in Japan Journal, (3)1.

Field, A. (2005). Discovering statistics using SPSS (2nd ed.). London: Sage Publications. 
Fry, E. (1989). Reading formulas: Maligned but valid. Journal of Reading, 32, 292-297.

Ghosts (n.d.). Retrieved August 5, 2009, from Wikipedia: http://en.wikipedia.org/ wiki/Ghosts

Grabe, W. (2009). Reading in a second language. Cambridge: Cambridge University Press.

Greenfield, J. (2004). Readability formulas for EFL. JALT Journal, 26, 5-24.

Hidi, S. (1990). Interest and its contribution as a mental resource for learning. Review of Educational Research, 60, 549-571.

Hidi, S. (2000). An interest researcher's perspective on the effects of extrinsic and intrinsic factors on motivation. In C. Sansone \& J. M. Harackiewicz (Eds.), Intrinsic motivation: Controversies and new directions (pp. 309-339). New York: Academic Press.

Hidi, S. (2001). Interest, reading, and learning: Theoretical and practical considerations. Educational Psychology Review, 13, 191-209.

Hidi, S., \& Baird, W. (1986). Interestingness-a neglected variable in discourse processing. Cognitive Science, 10, 179-194.

Hidi, S., \& Baird, W. (1988). Strategies for increasing text-based interest and students' recall of expository texts. Reading Research Quarterly, 23, 465-483.

Hidi, S., Berndorff, D., \& Ainley, M. (2002). Children's argument writing, interest, and self-efficacy: An intervention study. Learning and Instruction, 12, 429-446.

Hidi, S., \& Renninger, K. A. (2006). The four-phase model of interest development. Educational Psychologist, 41, 111-127.

Hudson, T. (1982). The effects of induced schemata on the short-circuit in L2 reading: Non-decoding factors in L2 reading performance. Language Learning, 32, 1-32.

Johnson, P. (1981). Effects on reading comprehension of language complexity and cultural background of a text. TESOL Quarterly, 15, 169-181.

Krapp, A., Hidi, S., \& Renninger, K. A. (1992). Interest, learning, and development. In K. A. Renninger, S. Hidi, \& A. Krapp (Eds.), The role of interest in learning and development (pp. 3-25). Hillsdale, NJ: Lawrence Erlbaum Associates.

Michael Jackson (n.d.). Retrieved August 5, 2009, from Wikipedia: http:// en.wikipedia.org/wiki/Michael_Jackson

Mitchell, M. (1993). Situational interest: Its multifaceted structure in the secondary school mathematics classroom. Journal of Educational Psychology, 85, 424-436. 
Renninger, K. A. (2000). Individual interest and its implications for understanding intrinsic motivation. In C. Sansone \& J. M. Harackiewicz (Eds.), Intrinsic and extrinsic motivation: The search for optimum motivation and performance (pp. 373-404). New York: Academic Press.

Robinson, P. (2003). Attention and memory during SLA. In C. J. Doughty \& M. H. Long (Eds.), The handbook of second language acquisition (pp. 631-678). Malden, MA: Blackwell Publishing.

Sadoski, M. (2001). Resolving the effects of concreteness on interest, comprehension, and learning important ideas from text. Educational Psychology Review, 13, 263-281.

Schiefele, U. (1996). Topic interest, text representation, and quality of experience. Contemporary Educational Psychology, 21, 3-18.

Schiefele, U. (1999). Interest and learning from text. Scientific Studies of Reading, 3, 257-279.

Schraw, G., \& Lehman, S. (2001). Situational interest: A review of the literature and directions for future research. Educational Psychology Review, 13, 23-52.

\section{Appendix A}

\section{Please read the following titles and descriptions of articles}

In response to the statements, circle a number from 1 to 6 ("1" means that you disagree very strongly and " 6 " means you agree very strongly).

\section{1. "Michael Jackson"}

This article is about singer Michael Jackson, his rise to fame and his descent into strange behavior and early death.

I think this article will be interesting to read.

$\begin{array}{llllll}1 & 2 & 3 & 4 & 5 & 6\end{array}$

I know much about the topic of this article.
1
2
3
4
5
6

2. "Concrete"

This article describes how concrete is made (its ingredients and methods for making it) and what it is used for. 
I think this article will be interesting to read.

$\begin{array}{llllll}1 & 2 & 3 & 4 & 5 & 6\end{array}$

I know much about the topic of this article.

$\begin{array}{lllllll}1 & 2 & 3 & 4 & 5 & 6\end{array}$

\section{Appendix B}

\section{Michael Jackson}

Michael Jackson was an American recording artist. He made his debut as an entertainer in 1968 as a member of The Jackson 5. That successful career led to him being dubbed the "King of Pop." Jackson's 1982 album Thriller remains the world's best-selling album of all time. His albums Bad, Dangerous, and HIStory also sold very well. One of the few artists to have been inducted into the Rock and Roll Hall of Fame twice, his other achievements include multiple Guinness World Records-including one for "Most Successful Entertainer of All Time"-13 Grammy Awards, 13 number one singles in his solo careermore than any other male artist in the Hot 100 era-and the sales of over 750 million records worldwide. Along with his musical success, Jackson's bizarre personal life, which included a pet chimp named Bubbles, sleeping in a special oxygen chamber (supposedly to prolong his life), dramatic whitening of his skin (it was rumored that Jackson was bleaching his skin), radical changes to his facial appearance because of many plastic surgeries (which resulted in his nose actually collapsing), and accusations of sexual molestation of boys, has made him a part of popular culture for almost four decades. President George $\mathrm{H}$. W. Bush presented the singer with The White House's special "Artist of the Decade" award in recognition of Jackson's musical influence in the 1980s.

\section{Music}

In the early 1980s, he became a dominant figure in American popular music and culture. He was the first African American entertainer to appear regularly on MTV. Videos such as "Black or White" and "Scream" made Jackson an enduring staple on MTV well into the 1990s. Jackson popularized some complicated dance techniques, such as the robot and the moonwalk, with his elaborate stage performances. His stunning performance on MTV's show celebrating the fiftieth anniversary of Motown Records has been compared to the Beatles' legendary appearance on the Ed Sullivan Show. Jackson donated and raised millions of dollars through his Heal the World Foundation. 


\section{Abused Child}

Jackson was abused by his father, Joseph Jackson, from a young age, enduring whippings and name-calling. In one altercation-later recalled by Jackson's brother Marlon Jackson-Joseph held Michael upside down by one leg and "punched him over and over again with his hand." Joseph would also trip or push his male children into walls. One night while Jackson was asleep, Joseph climbed into his room through the bedroom window. Wearing a fright mask, he entered the room screaming and shouting. Joseph said he wanted to teach his children not to leave the window open when they went to sleep. For years afterwards, Jackson said he suffered nightmares about being kidnapped from his bedroom. When Michael Jackson was on trial for child molestation years later, a psychiatrist who interviewed him said that because of this abuse, the singer was a "regressed 10-year-old," a child in a man's body, and was probably not capable of being a molester.

\section{Personal Life}

Michael Jackson's personal life generated significant controversy. Though he was accused of child sexual abuse in 1993, the criminal investigation was closed due to lack of evidence. Jackson was reported to have secretly paid his 13-year-old accuser 22 million dollars. During a documentary in 2003, Michael Jackson stated that he often had boys (visitors to Jackson's Neverland Ranch theme park) sleep overnight with him in his bed, and these were non-sexual "slumber parties." Jackson was later accused by two other boys of sexual abuse. He was tried and acquitted of abuse in 2005. While making a commercial for Pepsi, the singer's hair caught fire and his head was burned. Jackson later donated all of the 1.5 million dollars Pepsi paid him to a charity for burn victims. Falls while dancing caused a spinal injury and a broken nose, for which Jackson had his first experience with plastic surgery to his nose. Some report that he required much medicine for the pain from these injuries, which he began to take regularly. Over the years, he became very thin, and some claimed he was anorexic.

Jackson married twice (once to the daughter of Elvis Presley) and fathered three children. The mother of his first two children (Prince Michael Jackson and Paris Michael Katherine Jackson), Debbie Rowe, claims that she was impregnated by artificial insemination from an "unknown man." The mother of Jackson's third child (Prince Michael II) has never been identified. The singer died on June 25, 2009, after suffering cardiac arrest. Jackson's attempts to control the symptoms of injuries were probably related to his death. 


\section{Appendix C}

\section{Michael Jackson Comprehension Test}

1. The best-selling album of all time is called
a. Bad
b. Thriller
c. Dangerous
d. HIStory

2. Michael Jackson was given an "Artist of the Decade" award by
a. The Rock and Roll Hall of Fame
b. President George W. Bush
c. The Guinness Book of World Records
d. President George H. W. Bush

3. Some claimed that Jackson slept in a special oxygen chamber to
a. whiten his skin
b. help his breathing
c. extend his life
d. have private time with boys

4. Joe Jackson wore a fright mask at night
a. to teach Michael Jackson to keep the window shut
b. to push his children to not be lazy
c. because he enjoyed abusing his children
d. because Michael was having nightmares

5. In total, boys accused Michael Jackson of molestation.
a. 1
b. 2
c. 3
d. 4

6. From this article, we can understand that
a. Michael sometimes slept with a chimp.
b. in the 70s, MTV did not feature black musicians.
c. Michael was a child molester.
d. Michael was embarrassed about being African American.

7. The article implies that Joe Jackson
a. was a child molester
b. was jealous of his son's talent
c. was not violent with his daughters
d. had a bizarre sense of humor 
8. The article implies that
a. Jackson died because of use of pain drugs.
b. Debbie Rowe is the mother of Jackson's third child, but wants this to be a secret.
c. Michael gambled with his money and lost much of it.
d. Michael's pain medicine was expensive.

9. Michael Jackson
a. was willing to pay lots of money to charity.
b. was in financial trouble because of his relationships with boys
c. had spent too much money on plastic surgery
d. had money problems because his albums didn't sell well after Thriller and Bad.

10. Debbie Rowe implied that
a. she didn't want to be married to Michael Jackson
b. she wanted custody of two of the children.
c. she was angry about Michael having a third child without her.
d. Michael Jackson was not the father of any of the children. 